Research Article

\title{
Study on Deformation Law of Subway Construction under Passing Existing Line in Short Distance
}

\author{
Cong-Shuang Luo $\mathbb{D}^{\text {, }}$, Yi-Hong Cheng, Zhe Bai, Tong Shen, Xu-Yang Wu, \\ and Qing-Guo Wang
}

Henan University of Urban Construction, Pingdingshan 467036, China

Correspondence should be addressed to Cong-Shuang Luo; lcs128@163.com

Received 27 November 2020; Revised 17 January 2021; Accepted 28 January 2021; Published 9 February 2021

Academic Editor: Junhong Yuan

Copyright (C) 2021 Cong-Shuang Luo et al. This is an open access article distributed under the Creative Commons Attribution License, which permits unrestricted use, distribution, and reproduction in any medium, provided the original work is properly cited.

\begin{abstract}
With the large-scale development and utilization of underground space projects, the subway-led Rail Transit Project is developing vigorously, and the safety and stability of subway under passing existing projects have become a key issue for the future. In this paper, the deformation law of subway tunnel under the existing track is studied by using the method of ROCSCIENCE software and field measurement, which is based on the construction of a new double-tunnel shield-driven subway tunnel under the existing city of pile rapid track project. In the crossing area, the distance between the top of the tunnel and the pile foundation is $6.2 \mathrm{~m}$ and the distance between the tunnel and the existing track surface is $19.6 \mathrm{~m}$. It is required that the settlement of track caused by the new tunnel construction should not exceed $2 \mathrm{~mm}$. The results show that the settlement of the existing track is greatly influenced by the new tunnel without reinforcement and grouting, and the maximum settlement is more than $9.92 \mathrm{~mm}$. The settlement of the existing track can be controlled to $1.93 \mathrm{~mm}$ by adjusting the construction parameters of the shield machine and grouting reinforcement at different stages during construction.
\end{abstract}

\section{Introduction}

With the rapid development of urban rail transit, the urban overground and underground transportation network is becoming more and more intensive, and the distance between adjacent buildings is getting closer and closer, which will inevitably cause disturbance to the ground in the process of subway construction, safety, and environmental impacts on adjacent structures. In recent years, there are a lot of projects near the subway, especially the project of the subway passing through the existing project at close range, and many scholars have done a lot of research on the ground stability caused by the subway construction [1-4]. Lueprasert et al. [5] studied the deformation of the tunnel under crossloading pile-soil-tunnel interaction. Namazi et al. [6] studied the effects of double-tunnel excavation on underground passages. Sirivachiraporn and Phienwej [7] studied the effect of Metro Shield tunneling on nearby buildings. Pan et al. [8] carried out the safety and stability analysis of shield tunnel under the existing subway. Yang et al. [9] studied the effect of Double Line Shield tunnel construction technology on the frame structure. Guan et al. [10] analyzed the influence factors of the double-track tunnel passing through the existing track line in a short distance. Yang et al. [11] studied the effect of shield construction on the settlement of an existing subway tunnel. Zhang et al. [12] carried out the reinforcement optimization design for the Metro Shield tunneling under the existing railway; Lv et al. [13] studied the evaluation and treatment of the subway tunnel passing under the bridge at a short distance; Zhang [14] Studied the construction of a new subway tunnel to pass under the operating subway tunnel at a short distance; Yang and Wang [15] carried out a study on the settlement control of the tunnel passing through the subway station closely; Zhang et al. [16] carried out the deformation analysis of the adjacent Metro Shield tunnel; Liao et al. [17] studied the construction disturbance and control of subway tunnel passing through under the highway for a long distance. Most 
of the previous studies have investigated the effect of disturbance of a tunnel passing through a subway at a short distance by the numerical simulation [18-21].

In order to control the deformation of the adjacent buildings in subway construction, grouting has become an effective measure to control the deformation. In order to prevent the floating deformation of the existing structure under the shield excavation, Qi et al. [22] reinforced the soil within the span of the existing tunnel by grouting. Wu et al. [23] studied the effect of full-section grouting parameters on tunnel stability and reinforcement quality. Wu et al. [24] used grouting to reinforce the tunnel with a depth of $9 \mathrm{M}$, the reinforcement effect is good in the range of $2 \mathrm{M}$, and the deformation and failure can be controlled effectively. Li and Yuan [25] have studied the construction of a shield machine with a diameter less than $7 \mathrm{M}$, which can effectively control the settlement of the existing tunnel within $15 \mathrm{~mm}$ by compensating grouting. Bai et al. [26] established the extension theory model to evaluate the grouting effect of the water-rich sand bed. Zhu et al. [27] studied the effect of grouting rate on formation reinforcement in high-pressure jet grouting. Many scholars have studied the applicable conditions and reinforcement quality of high-pressure jet grouting. [28-31].

In the past, there was little research on subway tunnel construction under passing the urban rapid rail transit at a large angle. There is little research on grouting reinforcement in the whole process of large section shield tunnel. Based on the typical example of new large section shield tunnel construction under passing the existing line in a short distance, the whole process of grouting reinforcement in different stages of a new tunnel is simulated by using finite element software. In order to control the settlement deformation of urban fast track subgrade and track, grouting is used in three important construction stages of the tunnel. By analyzing the deformation law of existing railway track and subgrade, and comparing and analyzing the field monitoring data and numerical simulation results, the reliability of the model and the reinforcement effect of grouting reinforcement are verified, which provides a reference for similar projects.

\section{Engineering Overview and Geological Conditions}

2.1. Engineering Overview. The newly built subway tunnel is a double-tunnel single-track tunnel with a length of $3657 \mathrm{~m}$ and the thickness of overburden soil is $17.9 \mathrm{~m}$. The tunnel is constructed by a slurry shield machine with a diameter of $10.9 \mathrm{~m}$, the inner diameter of the tube slice is $9.5 \mathrm{~m}$, the outer diameter of the tube slice is $10.5 \mathrm{~m}$. The newly built subway tunnel runs under the existing track line at the range DK $45+210$ to DK45+290. The newly built tunnel cuts through the existing line at a large angle, which increases the cross distance and the construction difficulty. The cross area has high stratum sensitivity and the distance between shield machine and CFG pile is $6.2 \mathrm{~m}$, which brings a severe challenge to construction. The settlement of the tunnel under the existing track is not more than $2 \mathrm{~mm}$; otherwise, if the settlement is exceeded, the fast track will stop automatically. The horizontal and vertical relationship between the new tunnel and the existing track line is shown in Figures 1 and 2 .

2.2. Engineering Geological Conditions. There are miscellaneous fill, silty soil, fine sand, clay soil, and sandy soil in the area where the shield tunnel is located. The main structure of the new tunnel is in clay soil. The vertical relationship between the shield tunnel and the engineering geological conditions is shown in Figure 3.

2.3. Test Section Setting. Before the shield tunneling, a test section of shield construction is set up. The test section mileage is DK45 + $000 \sim \mathrm{DK} 45+200$ and the length is $200 \mathrm{~m}$. The construction parameters and reinforcement measures are optimized and adjusted through the construction of the test section.

2.4. Monitoring Point Arrangement. According to the evaluation report and design requirements, the vertical settlement value of the newly built subway tunnel shield under the existing track cannot be greater than $2 \mathrm{~mm}$. In order to ensure that the construction does not have a significant impact on the existing track, the strata and existing orbits need to be monitored and set an early warning limit. According to the construction requirements, it should monitor the existing track $120 \mathrm{~m}$ range of strata, subgrade, and track. The monitoring site layout is shown in Figure 4.

2.5. Reinforcement and Repair Scheme. In order to control the deformation of stratum and building (structure), in addition to adjusting the parameters of shield tunneling, grouting is adopted in different construction stages. According to the whole construction process, grouting reinforcement was carried out in different stages, including ground grouting reinforcement, dynamic compensation grouting, following grouting after passing through, and secondary grouting of tube pieces.

\subsubsection{Ground Advance Grouting Reinforcement.} Pregrouting pipe is used to reinforce the ground in the cross area before the shield crossing the existing line. There are 6 rows and 4 rows of 42 sleeve valves on both sides of the existing line. The sleeve valve tube length is $16-22 \mathrm{~m}$. The grouting distance is $50-100 \mathrm{~cm}$, the grouting speed is $10-100 \mathrm{~L} / \mathrm{min}$, and the grouting pressure is controlled at $0.4-1.0 \mathrm{MPa}$.

2.5.2. Dynamically Compensated Grouting. The synchronous dynamic compensation grouting should be carried out during the tunneling of the shield machine, which combines the synchronous grouting of the shield machine with the tracking compensation grouting. Cement and water glass double liquid slurry is used for grouting. The grouting pressure should be controlled within $0.5 \mathrm{MPa}$. 


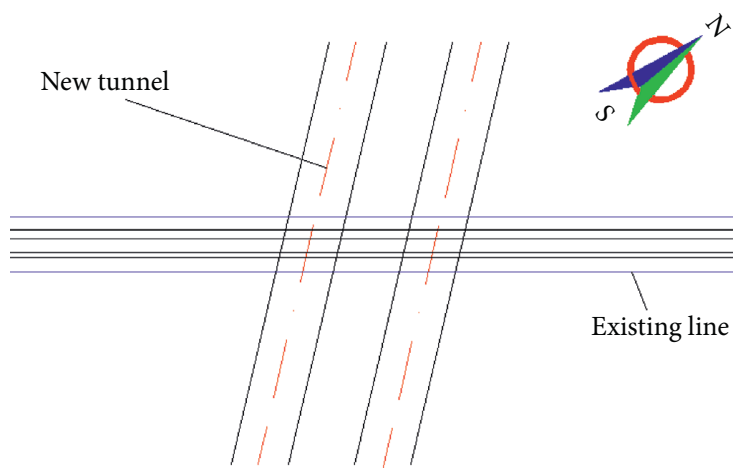

FIGURE 1: The horizontal relationship between the shield tunnel and existing track line.

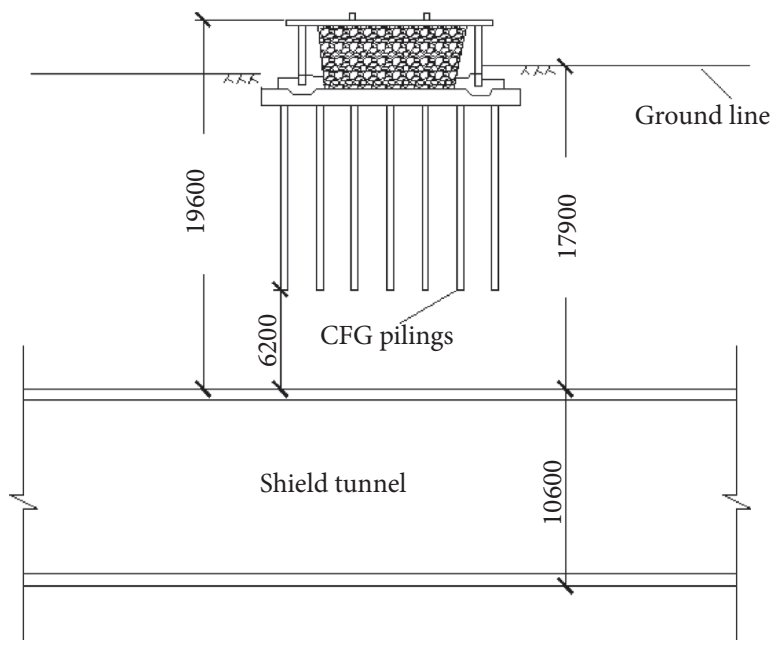

FIgURE 2: The vertical relationship between the shield tunnel and existing line.
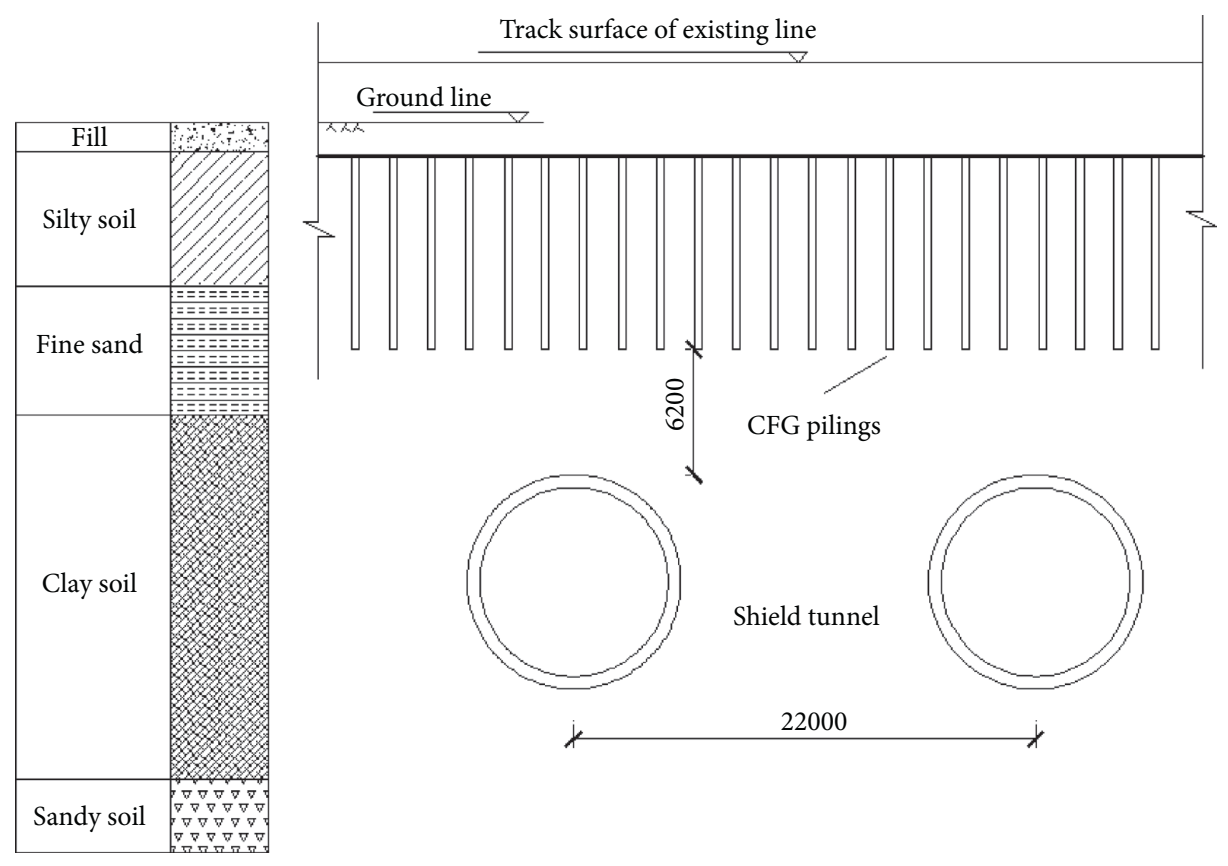

FIGURE 3: Engineering and geological section. 


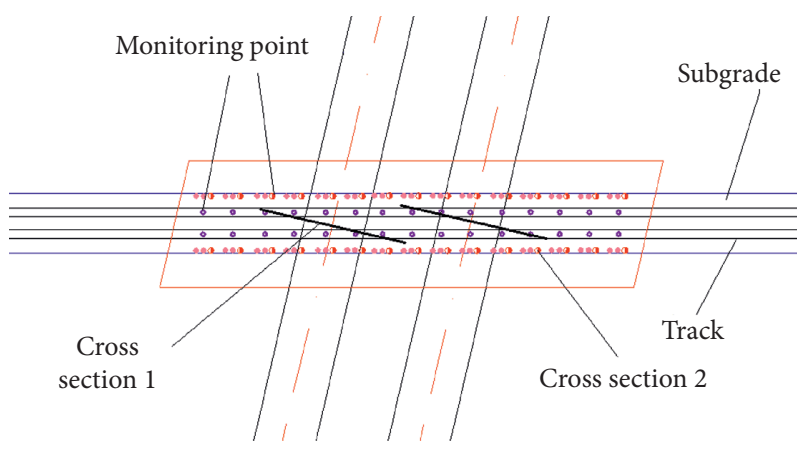

Figure 4: Monitoring site layout.

2.5.3. Following Grouting after Passing through. In order to prevent the settlement of the shield tail, grouting reinforcement should be carried out after the shield machine passes through. The grouting step is $50 \sim 100 \mathrm{~cm}$ and the grouting speed is $10 \sim 100 \mathrm{l} / \mathrm{min}$. The grouting interval is $24 \mathrm{~h}$ with step-back grouting.

2.5.4. Secondary Grouting of Tube Pieces. The special segments with 25 grouting holes in each ring are selected to reinforce the secondary deep hole grouting in the main influence area of shield tunneling. The length of grouting pipe embedded in the secondary grouting holes of each ring is $3 \mathrm{~m}$.

\section{Numerical Modeling}

In order to predict the possible engineering disasters during the construction period, this paper simulates the influence of subway tunnel underpass construction on the stratum and track. The numerical simulation can provide the scheme design and parameter optimization for the construction, so as to reduce the disturbance and damage of the upper building caused by shield construction.

3.1. Model Building. In combination with the actual situation of this project, the ROCSCIENCE analysis software is selected to establish the numerical model, as shown in Figure 5.

3.2. Parameter Selection. The parameters of each soil layer in the model are selected and confirmed according to the engineering geological survey data. In the numerical model, the soil is considered an ideal elastoplastic material. Hence, the constitutive relationship can be described by the modified Mohr-Coulomb constitutive mode. The soil layer and structure parameters required for the numerical simulation are shown in Table 1. The calculating parameters of structural elements are shown in Table 2.

3.3. Construction Procedures. In order to reduce the influence of the double-tunnel undercrossing on the existing track above, the double-tunnel was excavated by staggered excavation. The left and right tunnels are not constructed at the same time. The

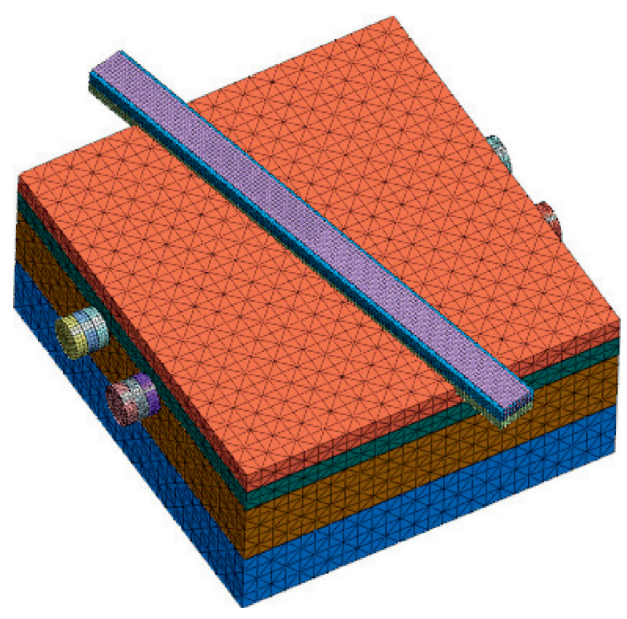

Figure 5: Numerical simulation model.

left-line tunnel is constructed first, and the right-line tunnel is constructed after the left-line tunnel has passed through the existing line. The construction procedure is shown in Figure 6.

\section{Results and Analysis}

4.1. Numerical Simulation and Result Analysis. Two working conditions are simulated by the software. The first working condition is the deformation analysis of the track and subgrade during the shield construction without grouting reinforcement measures. The second working condition is the deformation analysis of track and subgrade after grouting in four stages. In the first working condition, the vertical and horizontal displacements are shown in Figures 7 and 8 .

According to the numerical simulation analysis before construction, the new double-tunnel tunnel will have great influence if it passes through the existing line completely without any support. The maximum ground settlement reaches $9.89 \mathrm{~mm}$, which exceeds the engineering limit requirement. The maximum horizontal displacement reaches $4.24 \mathrm{~mm}$.

When a large-diameter shield machine is used for construction in a shallow depth, it will disturb and destroy the adjacent pile foundation and stratum. The advance settlement will occur in the front during construction and excavation. The shield machine passing through the intersecting area will cause the deformation and settlement of the rock and soil layer. When the shield passes through, there will be large settlement deformation in the tail of the shield and later period of excavation. The sensitivity of strata in this area is high, and it is easy to produce deformation and failure under construction disturbance. The large angle intersection of the two lines and the increase of the intersection distance cause the complicated alternation of the soil layer structure, which is easy to be deformed and destroyed. These aspects are the main factors leading to the large deformation in the region. During the construction, reinforcement must be taken to control the deformation of the ground and upper track within $2 \mathrm{~mm}$. 
TABle 1: Physical and mechanical properties of soils.

\begin{tabular}{lcccccc}
\hline Soil type & Thickness $(\mathrm{m})$ & Density $\left(\mathrm{g} \cdot \mathrm{cm}^{-3}\right)$ & Internal friction angle $\left(^{\circ}\right)$ & Cohesion $(\mathrm{kPa})$ & Poisson's ratio & Elastic modulus $(\mathrm{MPa})$ \\
\hline Fill & 1.5 & 1.75 & 5 & 10 & 0.3 & 12.0 \\
Silty soil & 6.5 & 1.96 & 15.1 & 46.0 & 0.25 & 45.0 \\
Fine sand & 6.5 & 2.05 & 27 & - & 0.3 & 45.0 \\
Clay soil & 18 & 2.01 & 16.8 & - & 0.3 & 3.3 \\
Sandy soil & 21 & 2.02 & 27 & -3 & 0.3 & 48.0 \\
\hline
\end{tabular}

TABLE 2: Calculating parameters of structural elements.

\begin{tabular}{lcccc}
\hline Type & Material & Density $\left(\mathrm{g} \cdot \mathrm{cm}^{-3}\right)$ & Poisson's ratio & Elastic modulus $(\mathrm{GPa})$ \\
\hline CFG pile & C20 & 2.5 & 0.2 & 25 \\
Subgrade & C30 & 2.5 & 0.2 & 30 \\
Tube slice & C50 & 2.5 & 0.25 & 34 \\
Grouting layer & Grouting and strengthening soil layer & 2.0 & 0.3 & 68 \\
\hline
\end{tabular}

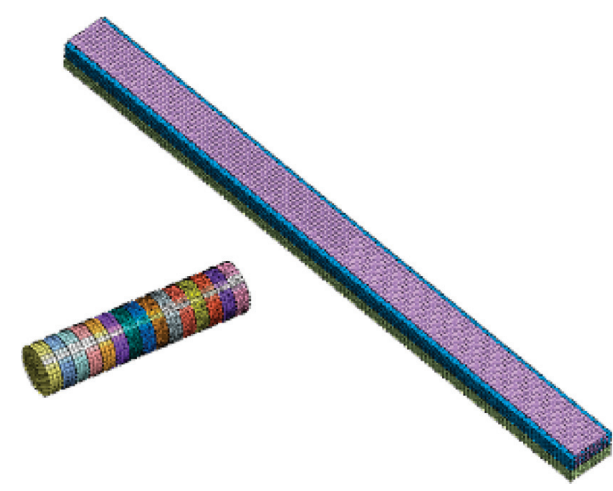

(a)

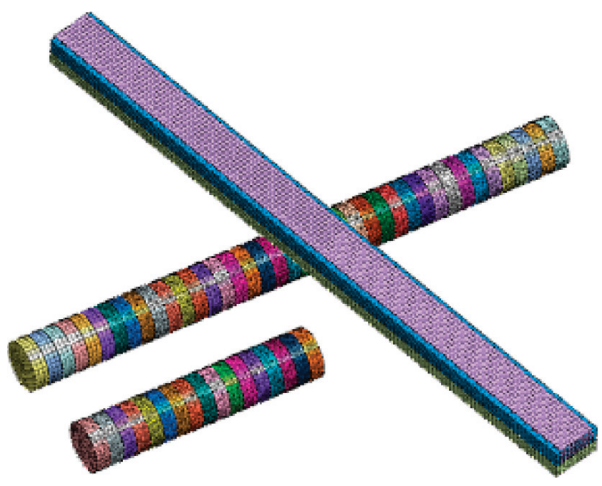

(c)

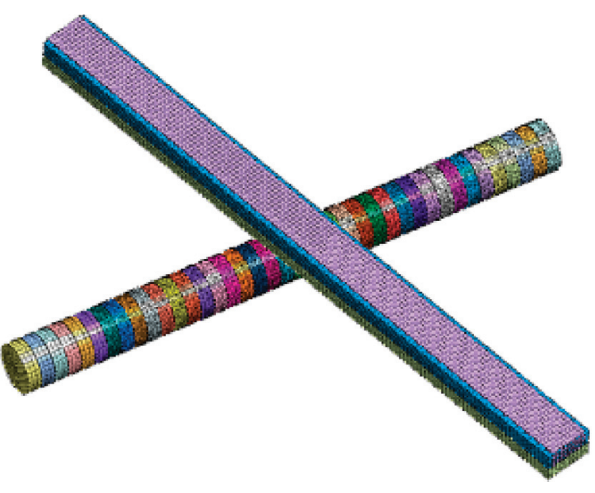

(b)

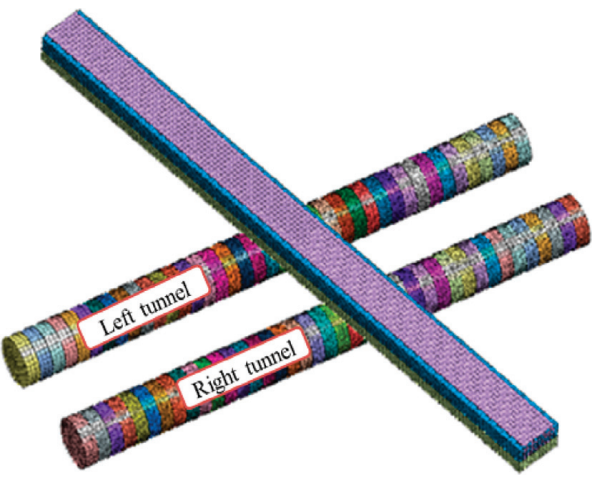

(d)

Figure 6: Construction order diagram. (a) Left tunnel construction. (b) The left tunnel cuts through the existing line. (c) Right tunnel construction (d) The right tunnel cuts through the existing line.

In order to control the deformation of the stratum and superstructure caused by shield construction, we adopted grouting reinforcement measures. By adjusting the attitude of the shield machine and grouting reinforcement in each stage, the deformation and failure of the stratum and superstructure are effectively controlled. The settlement and deformation of the subgrade and track are shown in Figure 9.

As can be seen from Figure 9, the settlement deformation has been effectively controlled by comprehensive measures such as ground reinforcement before shield tunneling, simultaneous grouting during tunneling, grouting around shield tunneling, and adjustment of shield attitude. The settlement deformation of the existing track is $1.93 \mathrm{~mm}$ in the shield construction, which is controlled within the construction deformation of $2 \mathrm{~mm}$ to meet the construction requirements and ensure that the shield underpass has no influence on the operation of the existing track. 


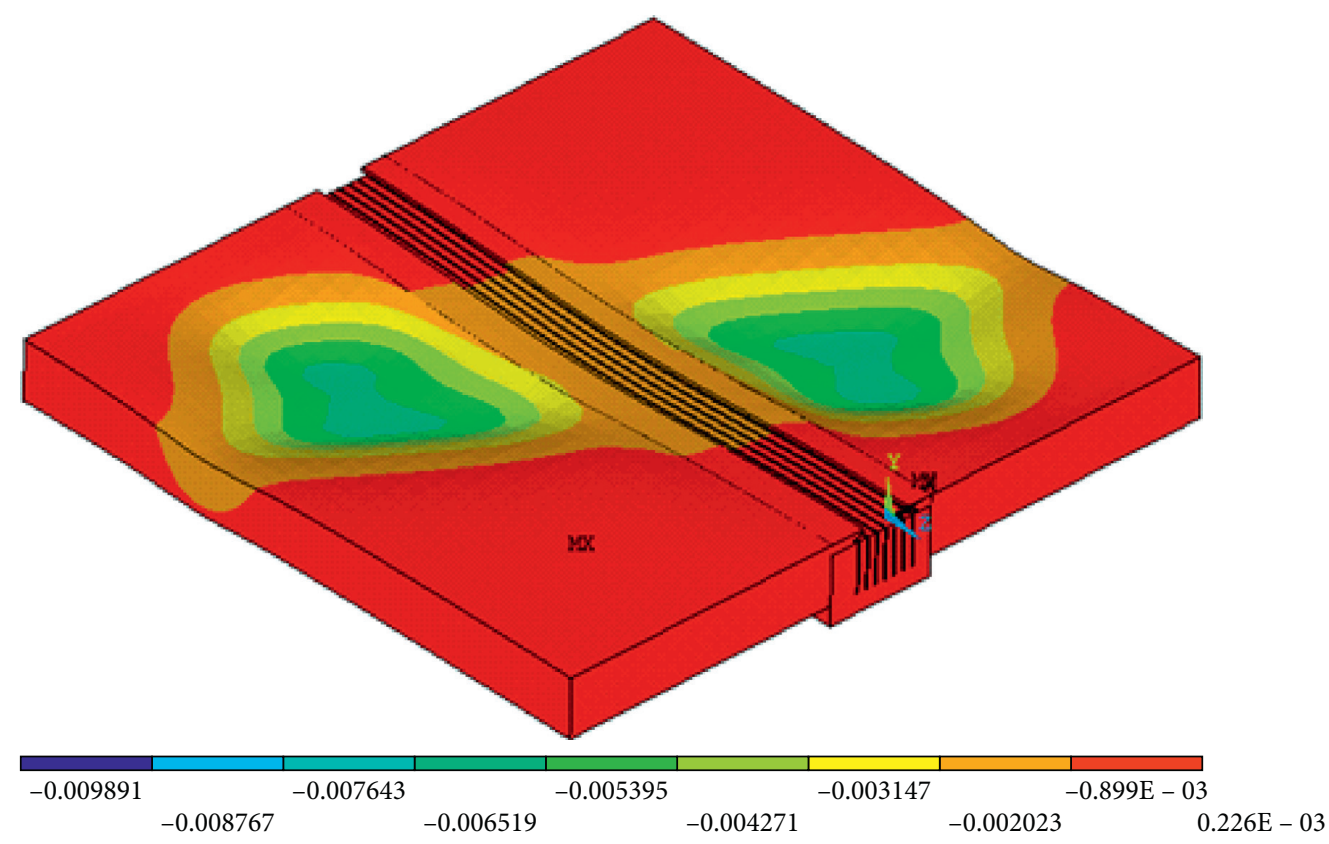

Figure 7: Numerical simulation of settlement map.
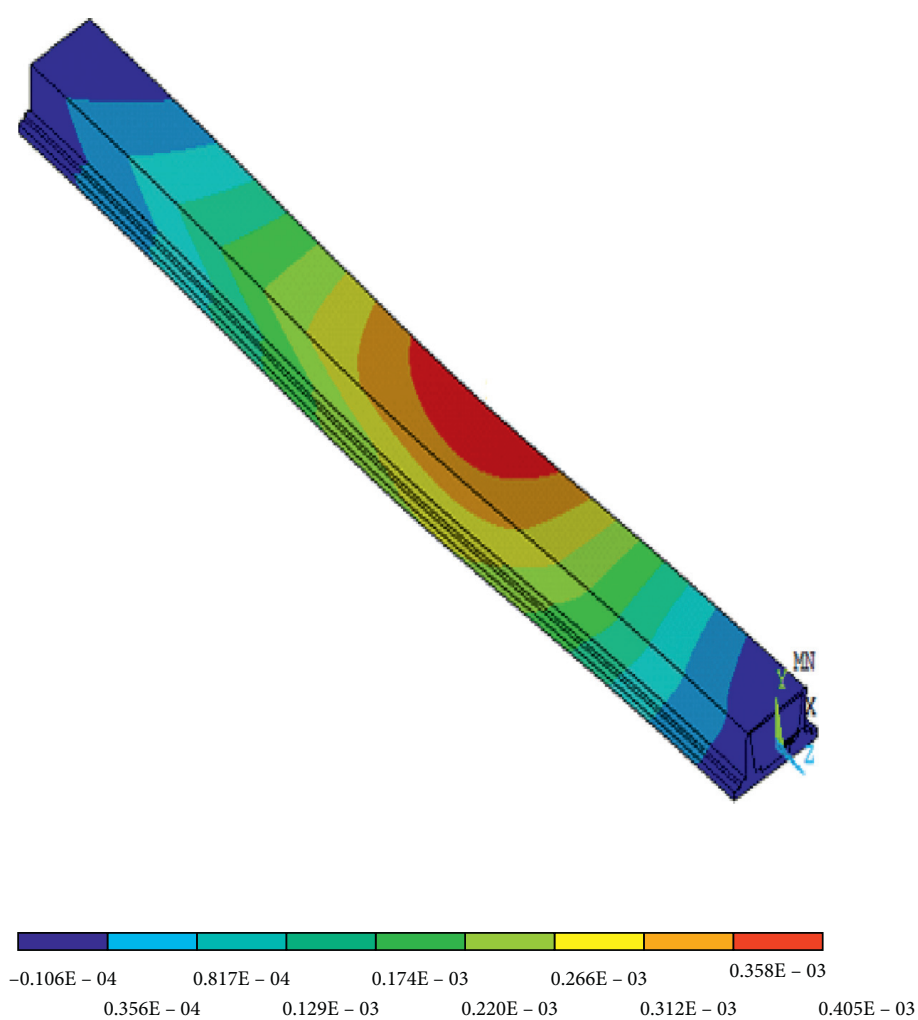

(a)
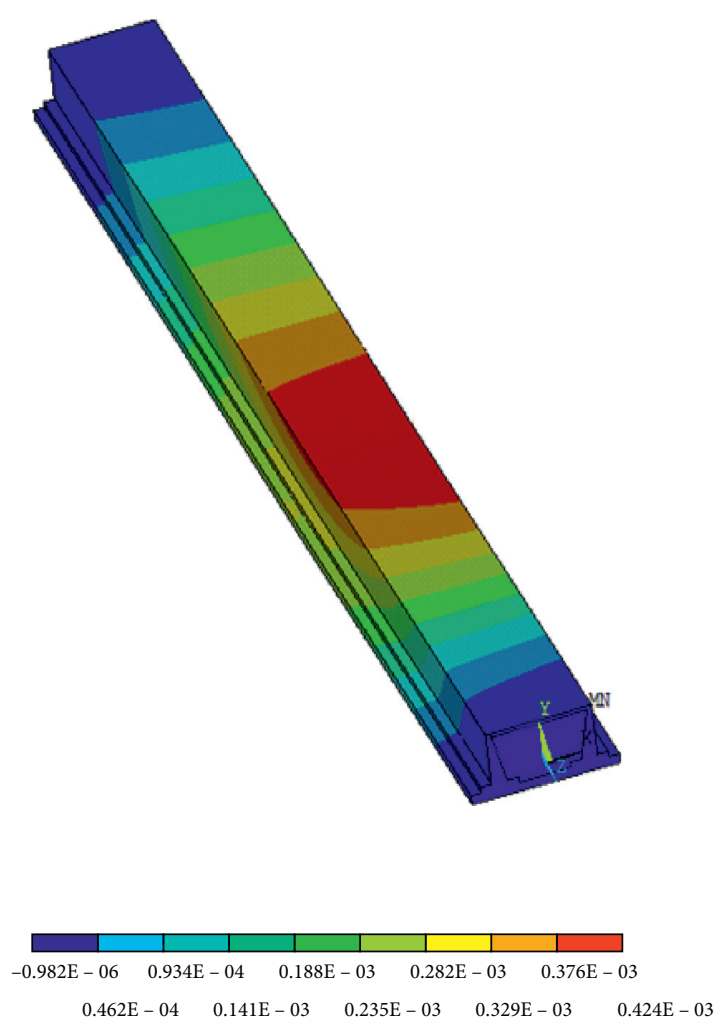

(b)

Figure 8: Horizontal displacement. (a) Left-line underpass. (b) Right-line underpass.

4.2. Results and Analysis of the Test Section. According to the vertical displacement of the stratum in the course of the shield tunnel passing through the existing line in the test section, the tunnel construction has a serious safety impact on the existing line. Without grouting reinforcement, the shield construction has a great influence on the stratum and the existing line. The cumulative settlement curves of the left and right lines are shown in Figures 10 and 11. 


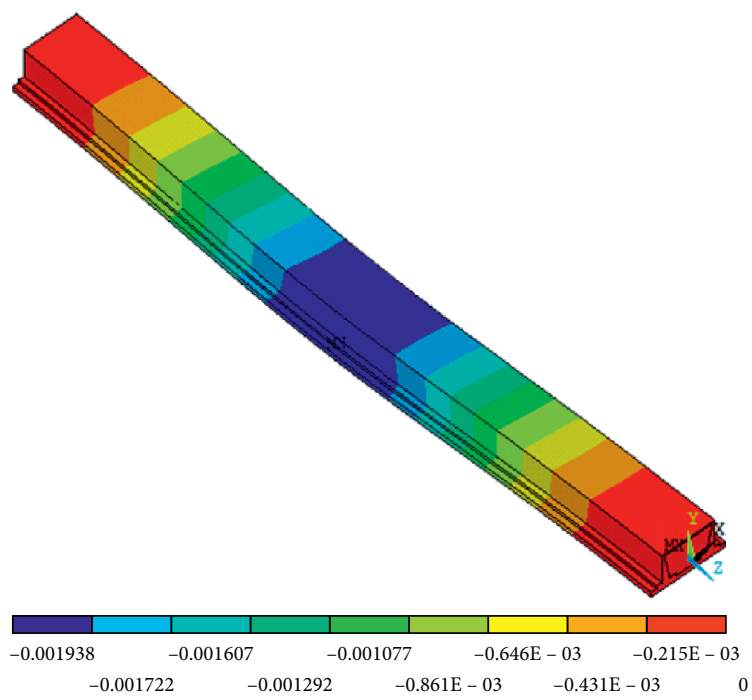

Figure 9: Construction effect after grouting.

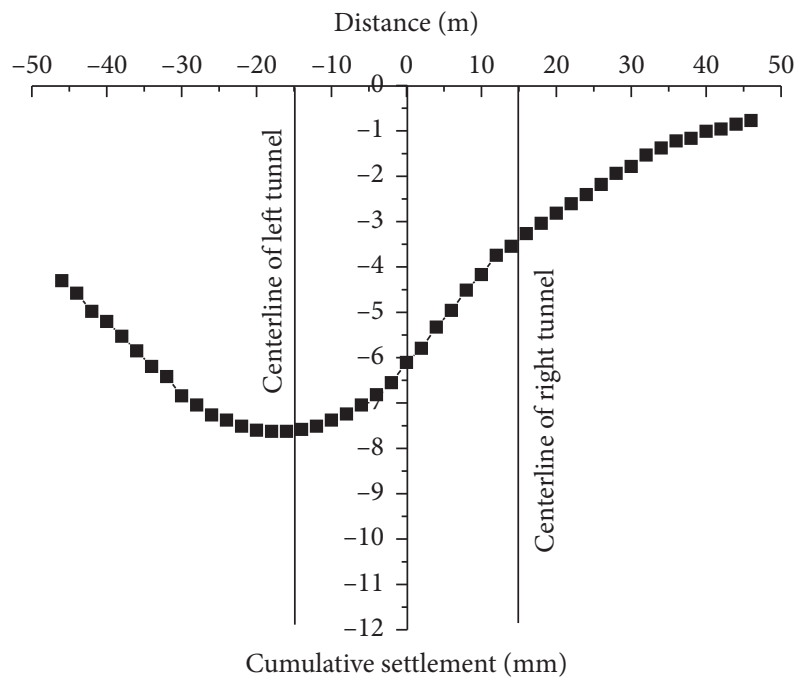

Figure 10: Cumulative settlement of left-line tunnel underpass.

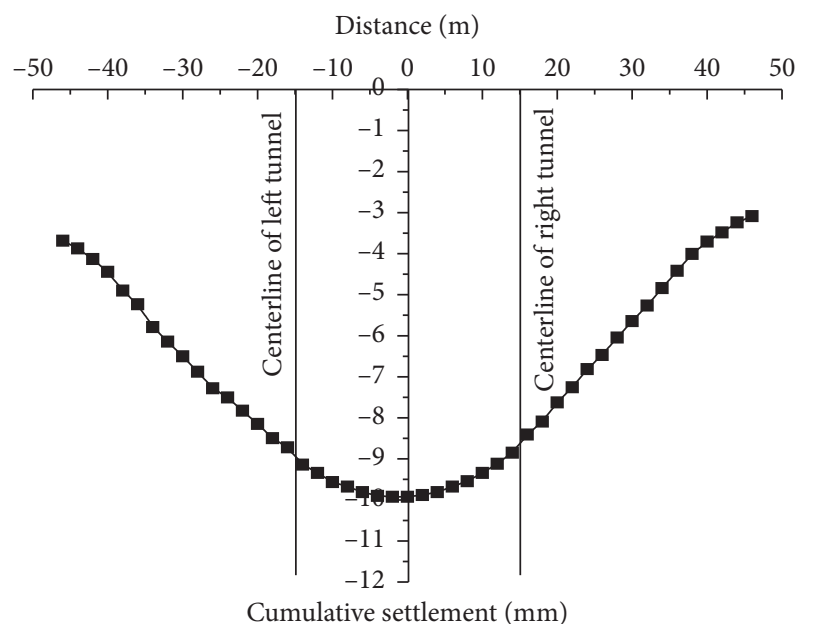

Figure 11: Cumulative settlement of right-line tunnel underpass.
As can be seen from Figures 10 and 11, the left-hand side shield will cause larger ground settlement, with the maximum settlement able to reach $8.46 \mathrm{~mm}$ and the influence range mainly about 50 meters from the centerline of the tunnel. When the right line shield goes through, the accumulative settlement will occur, and the maximum settlement depth can reach $9.92 \mathrm{~mm}$.

The factors and reasons of ground surface deformation are obtained by shield construction in the test section. There are five stages of settlement in shield tunneling; they are first settlement, settlement in front of excavation, through settlement, settlement in the gap of shield tail, and later settlement. The settlement time curves produced by the passing of the left and right line shield are shown in Figures 12 and 13. The settlement ratios of the two cross sections are shown in Figures 14 and 15.

According to Figure 12, the main influence area is within $25 \mathrm{~m}$ of the middle line, when the left line of the shield passes through the cross section. In this range, the accumulative settlement is larger, especially in the upper position of the centerline of the left line, and the accumulative settlement is close to $8 \mathrm{~mm}$. As can be seen from Figure 13, when the right line passes through the cross section, it will cause secondary disturbance to the left line, resulting in the ground settlement above the left line being greater than the right line. The settlement on the left line is close to $10 \mathrm{~mm}$.

As can be seen from Figure 14, when the left line of the shield passes through the cross section area, the settlement generated is mainly the settlement in front of the development face, the settlement through the settlement, and the settlement in the void of the shield tail. As can be seen from Figure 15, when the right line of the shield passes through the cross section area, the settlement generated is mainly through the settlement and the clearance of the shield tail. The whole process of shield machine crossing the crossing area is the main factor that causes the deformation of stratum and superstructure, so controlling the construction process of shield machine is the main section to ensure the 


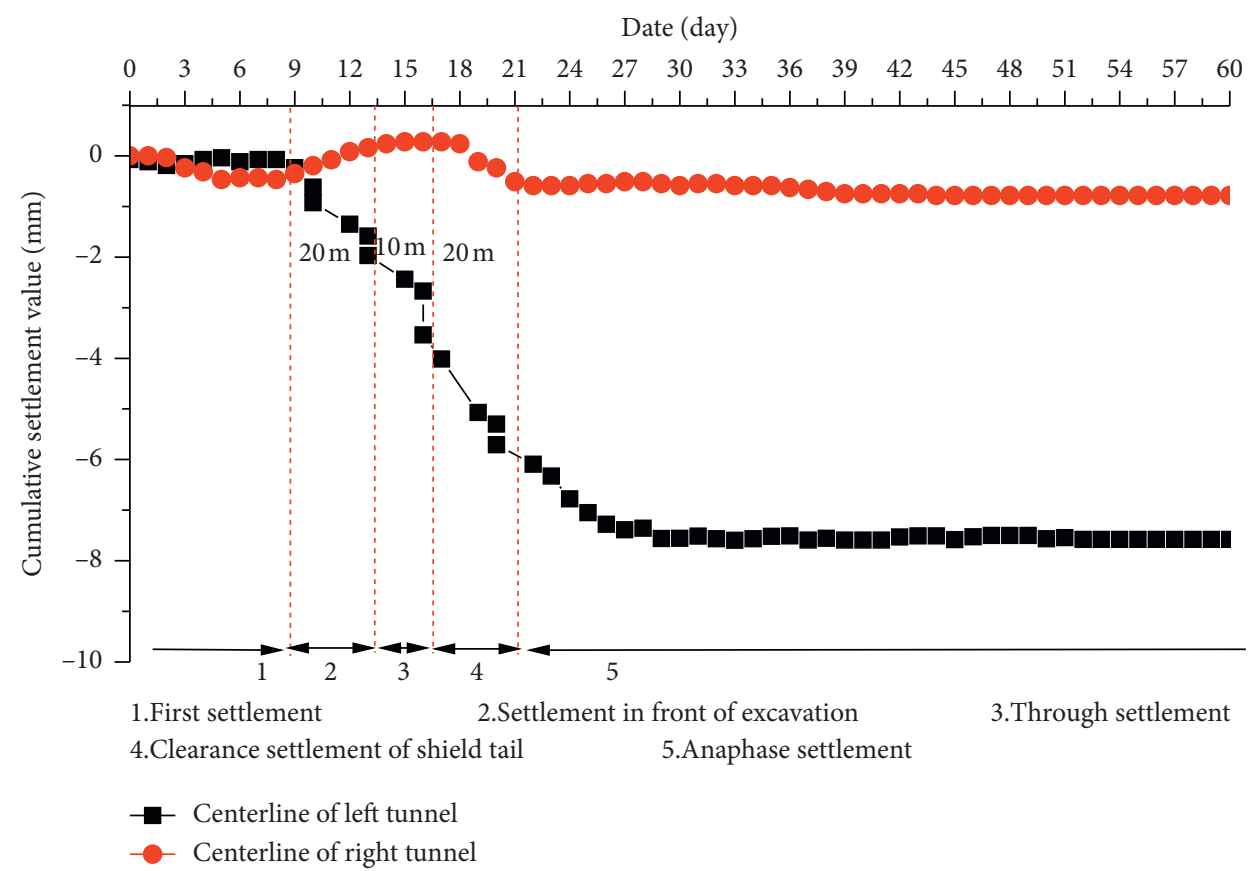

Figure 12: The settling time curve of the ground when the left-line shield passes through (test section).

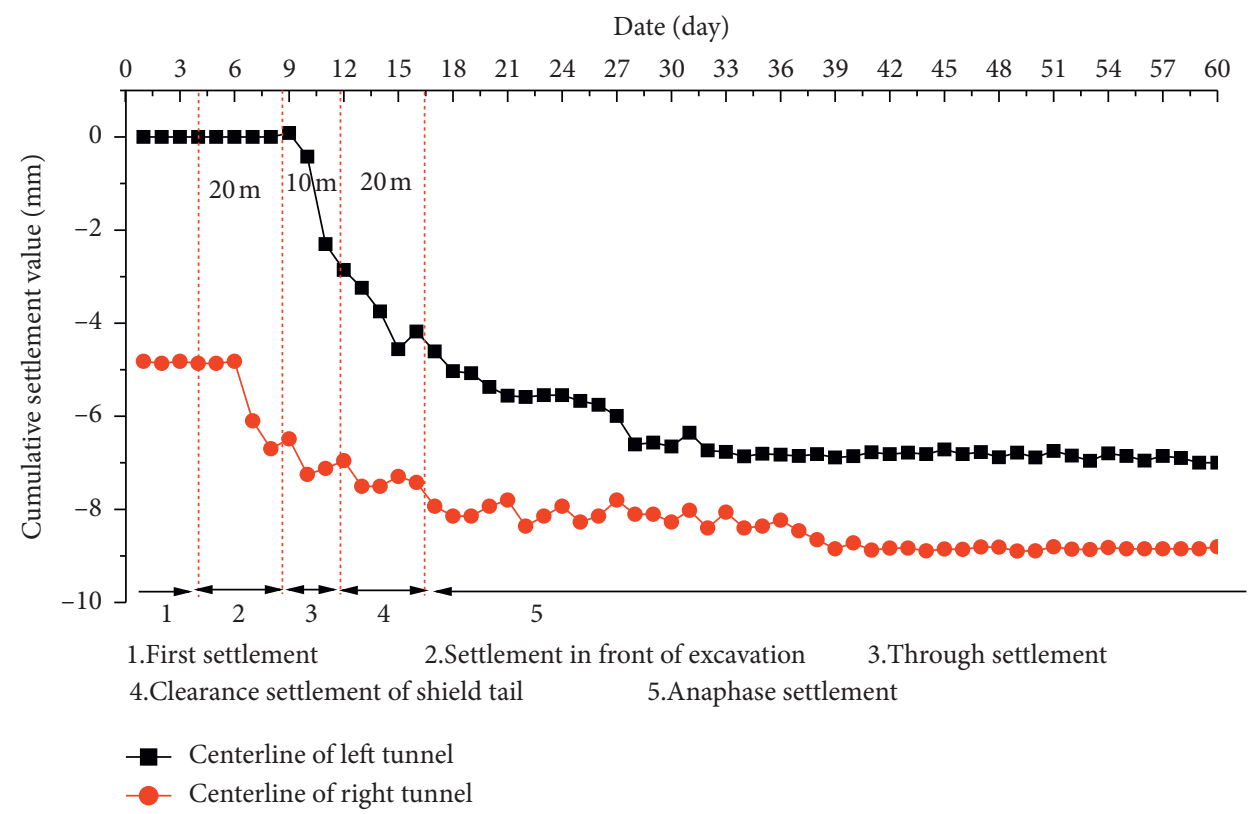

FIgURE 13: The settling time curve of the ground when the right-line shield passes through (test section).

settlement of the upper track and subgrade. We must carry on the reinforcement processing to the shield construction entire process.

4.3. Analysis of Grouting Reinforcement Effect. The influence of shield construction on settlement deformation of track and subgrade is reduced by grouting reinforcement in different stages and links. The settlement time curves produced by the passing of the left and right line shield are shown in Figures 16 and 17. The settlement ratios of the two cross sections are shown in Figures 18 and 19.

As can be seen from Figures 16 and 17, the settlement of the surface and superstructure is controlled within $2 \mathrm{~mm}$ by grouting reinforcement and adjusting the parameters of the shield machine in each stage. As can be seen from Figures 18 and 19, when the left and right lines pass through, the settlement deformation is mainly concentrated in the last 


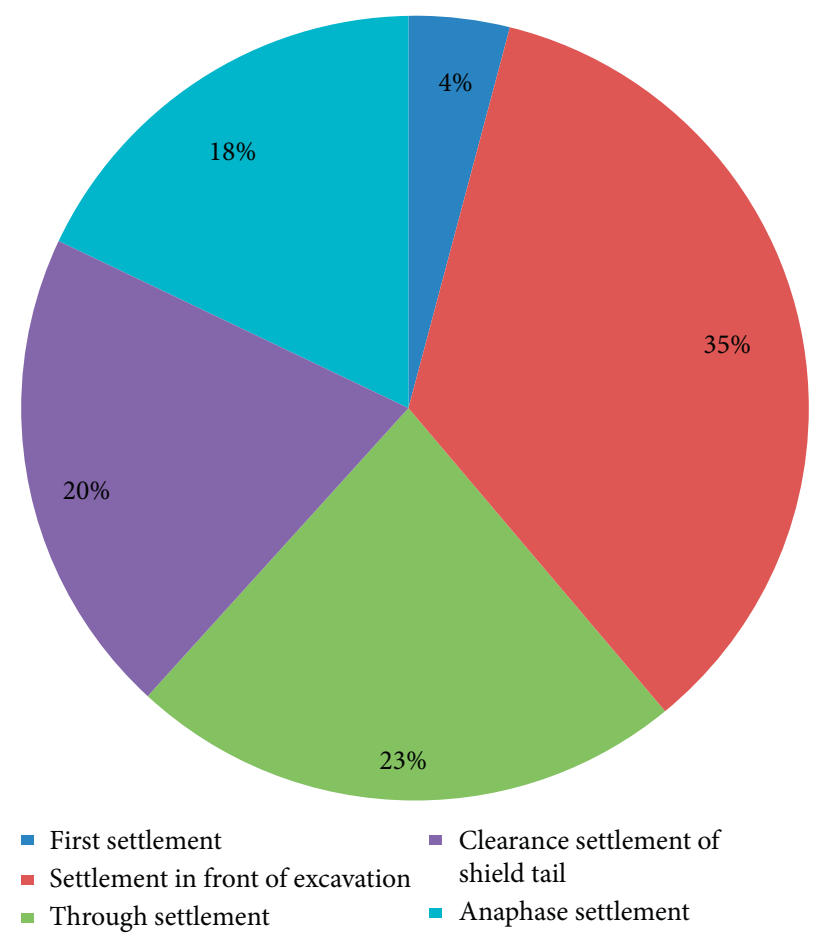

FIgURE 14: Settlement scale map of cross section 1 (test section).

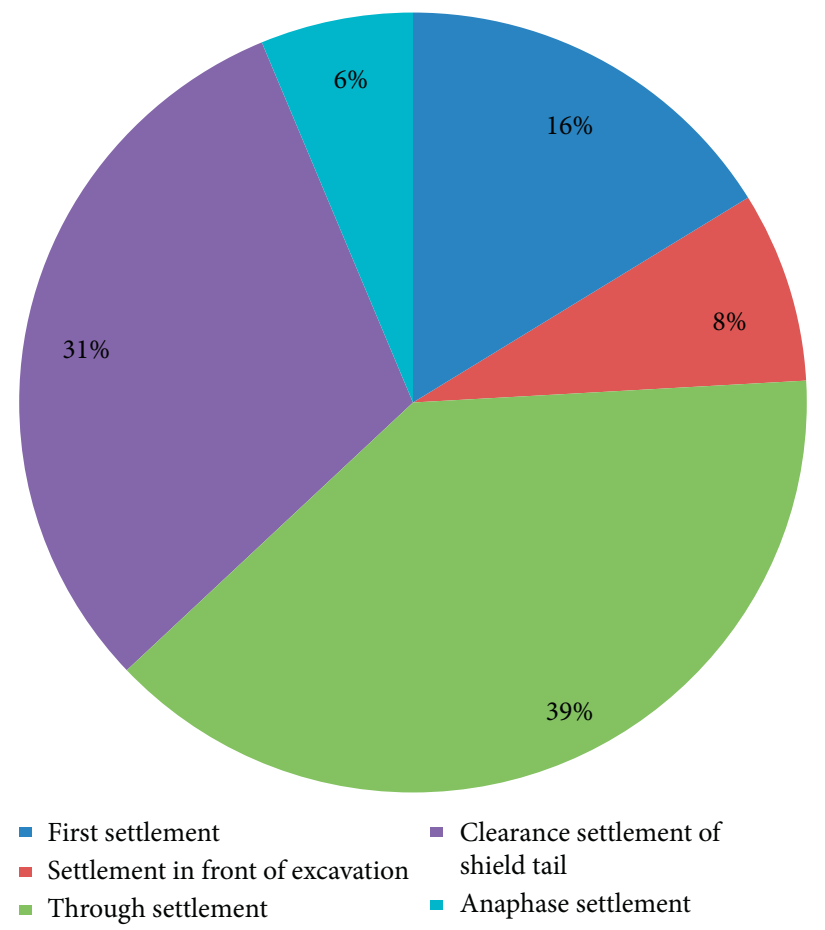

FIGURE 15: Settlement scale map of cross section 2 (test section).

three stages. In particular, the through settlement and clearance settlement of shield tail are more obvious. By grouting reinforcement, the settlement at the later stage is reduced greatly.
According to the results of numerical simulation and the construction test of the test section, we adjust and optimize the construction scheme. During the construction of subway shield tunneling, the track and subgrade are monitored on 


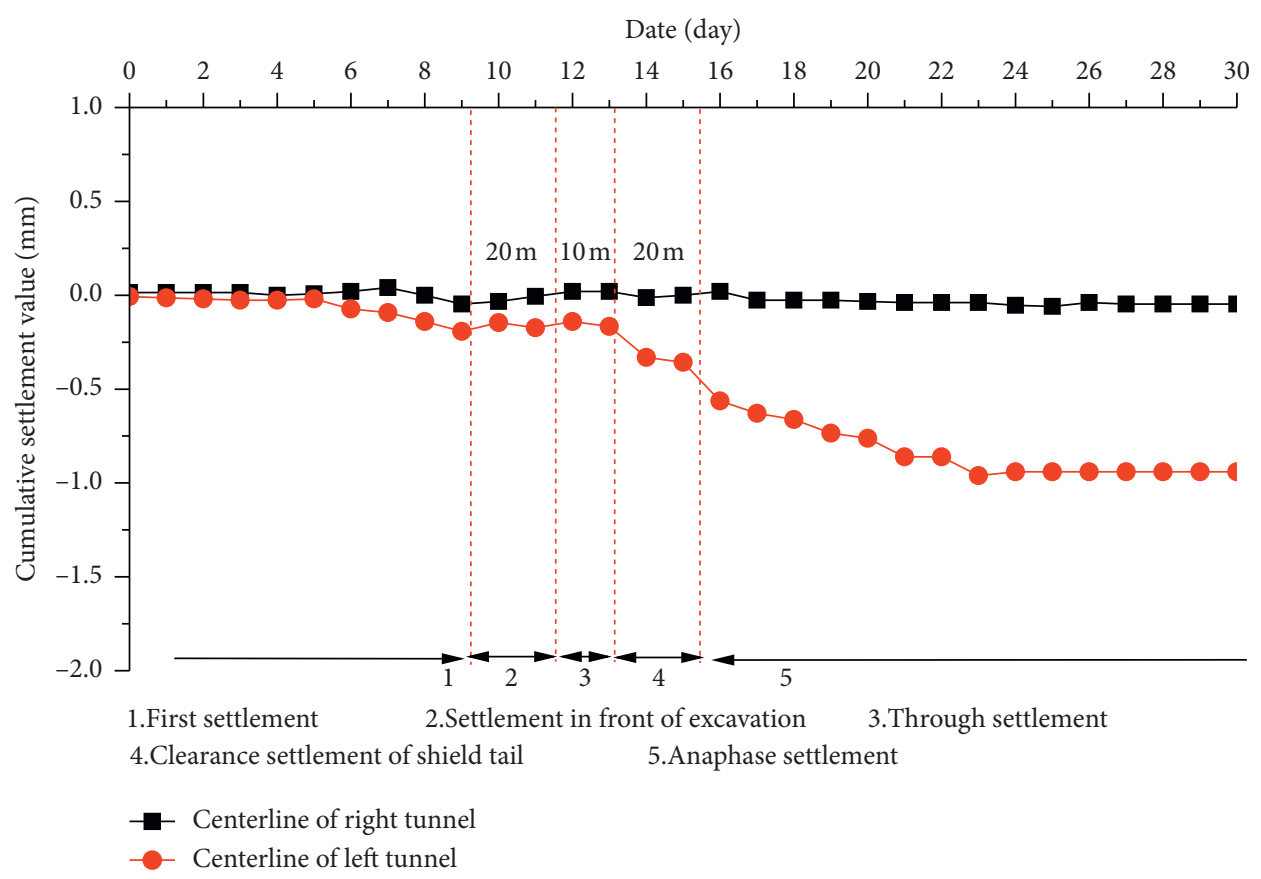

Figure 16: The settling time curve of the ground when the left-line shield passes through (grouting reinforcement).

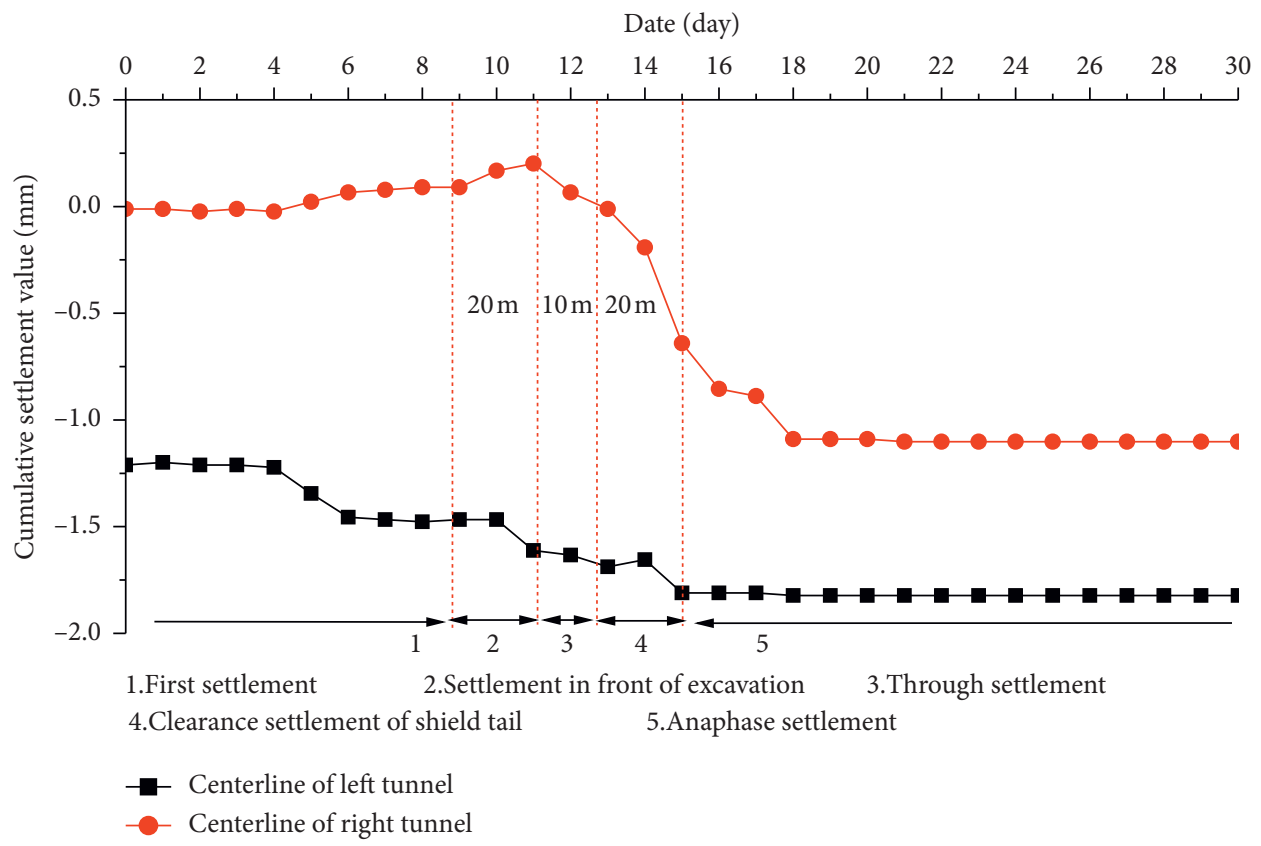

FIGURE 17: The settling time curve of the ground when the right-line shield passes through (grouting reinforcement).

site. The settlement curve of the subgrade and track structure is shown in Figures 20-22.

As can be seen from Figures 20-22, the settlement of subgrade structure and track is less than $2 \mathrm{~mm}$ after grouting and other reinforcement measures.

For the influence of the construction of the existing track line, the left tunnel constructed first will have a great influence on the existing line, while the right tunnel constructed later will have a superposition influence, and the right tunnel constructed will have repeated and accumulative settlement. By adjusting the parameters of the shield machine and the synchronous grouting, the settlement deformation of the small distance shield under the existing line can be effectively controlled.

4.4. Comparison of Numerical Simulation and Monitoring Results. In this paper, the influence of shield construction 


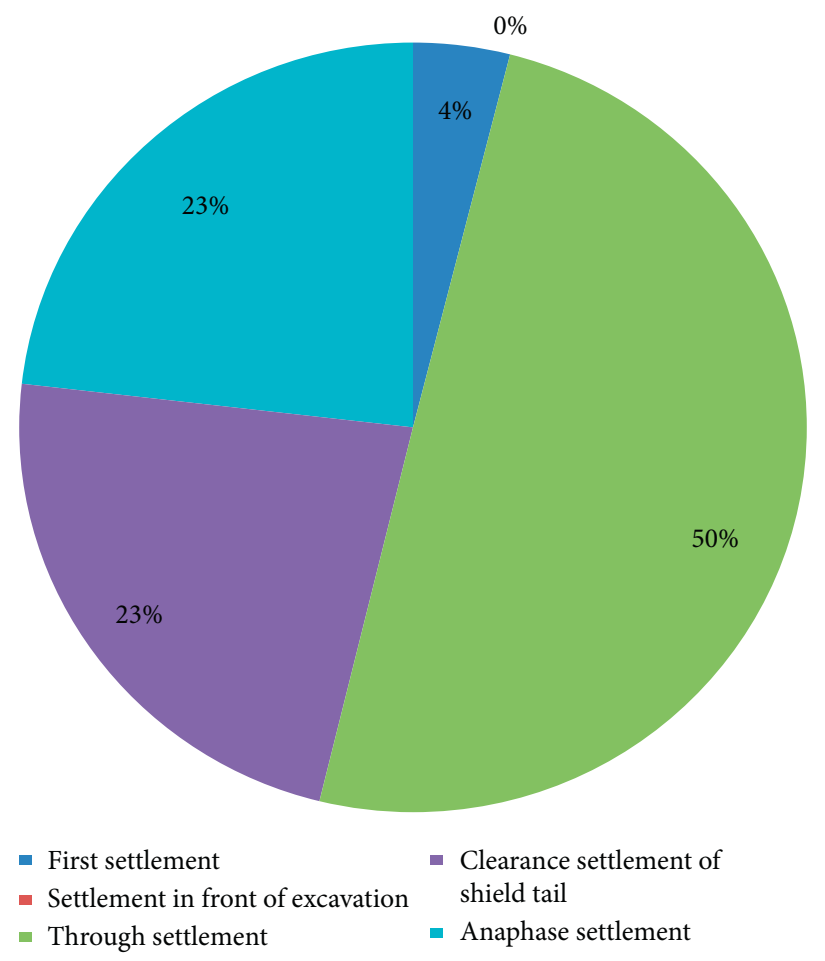

Figure 18: Settlement scale map of cross section 1 (grouting reinforcement).

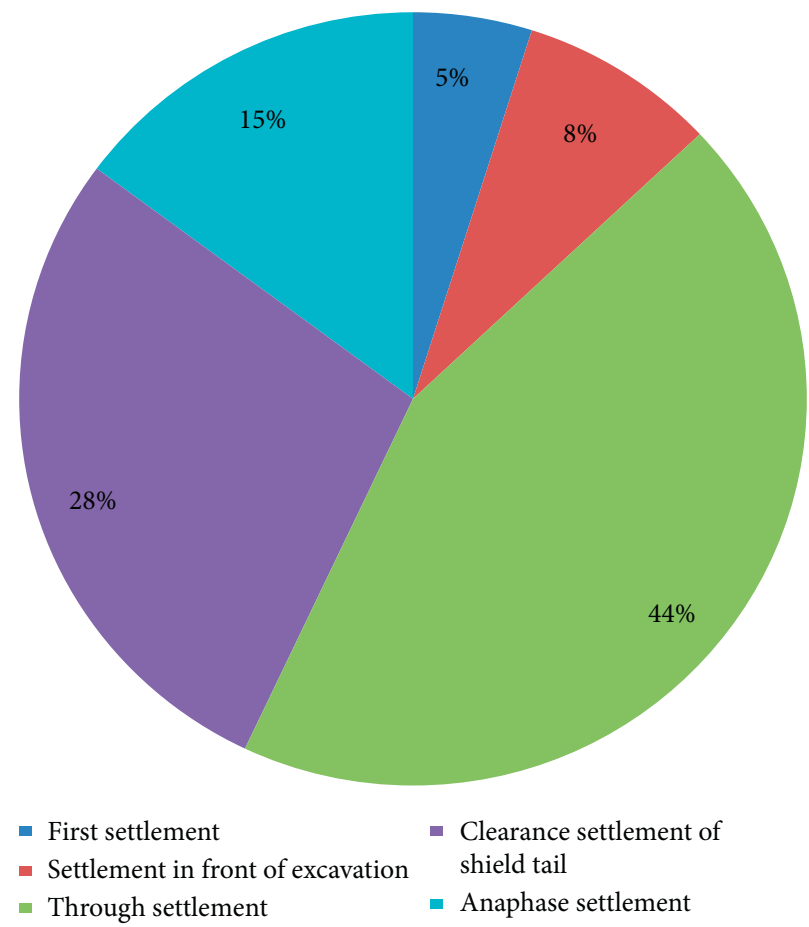

FIGURE 19: Settlement scale map of cross section 2 (grouting reinforcement). 


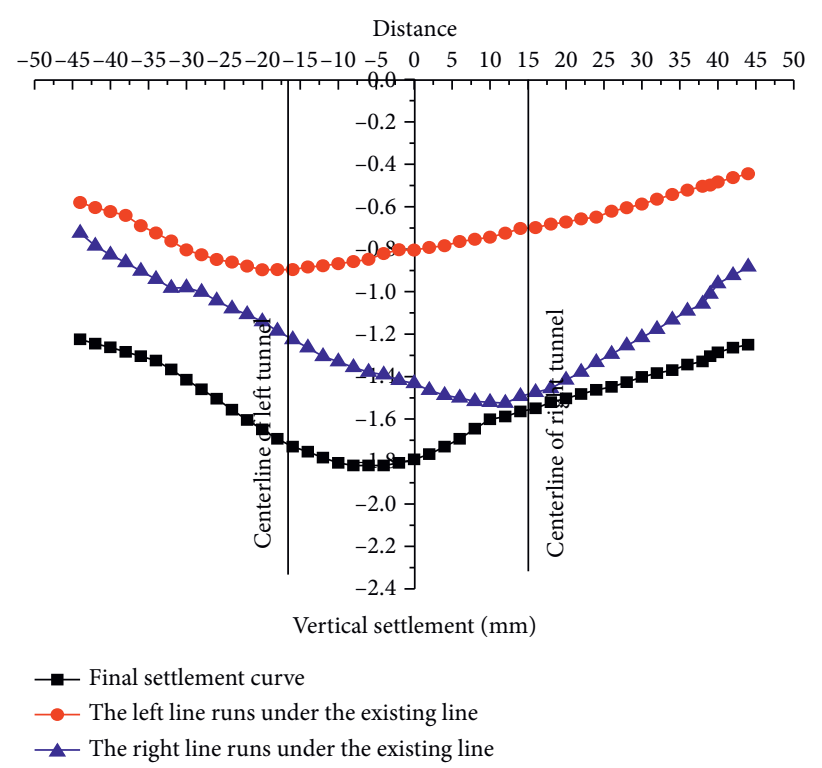

FIgURE 20: Settlement curve of subgrade structure after double-tunnel penetration.

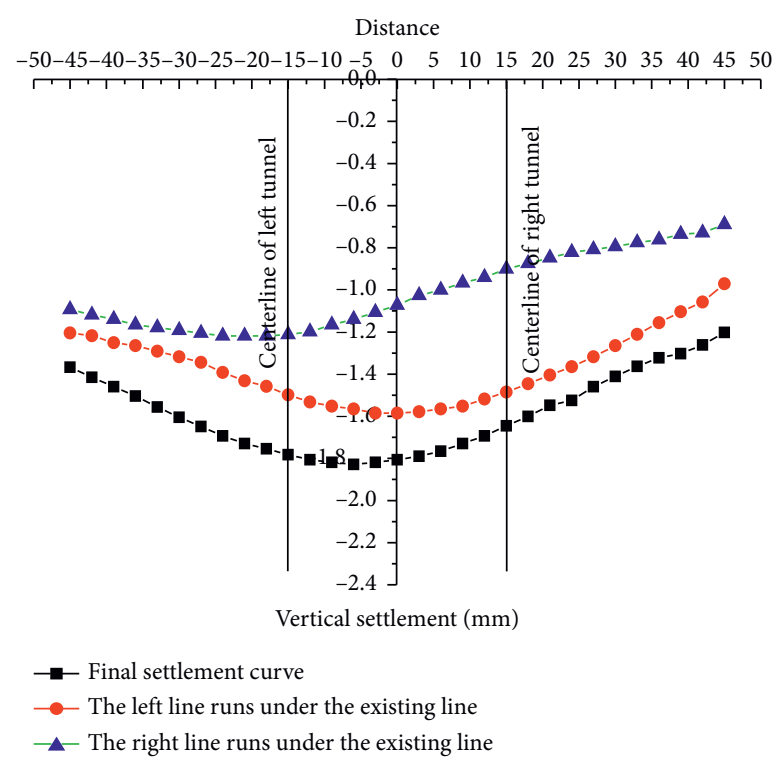

FIgURE 21: Settlement curve of track structure after double-tunnel penetration.

on the deformation of the existing track is studied by numerical simulation and field monitoring. The comparison between numerical simulation and field monitoring is shown in Table 3.

The settlement value and settlement trend of the existing track structure are basically the same as those of the roadbed structure. The maximum settlement of track and subgrade is located directly above the left-line tunnel when the left-line tunnel crosses the cross section. After the construction of left-right line tunnel, the maximum settlement of the track subgrade is $9.92 \mathrm{~mm}$, which is located in the middle of the left-right line tunnel. The maximum settlement of track and subgrade is $1.82 \mathrm{~mm}$ by adjusting the attitude of the shield machine and grouting reinforcement in each stage, which meets the construction standards and requirements. The results of numerical simulation and field monitoring are basically consistent with an error of 5.6\%. The numerical simulation results can provide a reference for field 


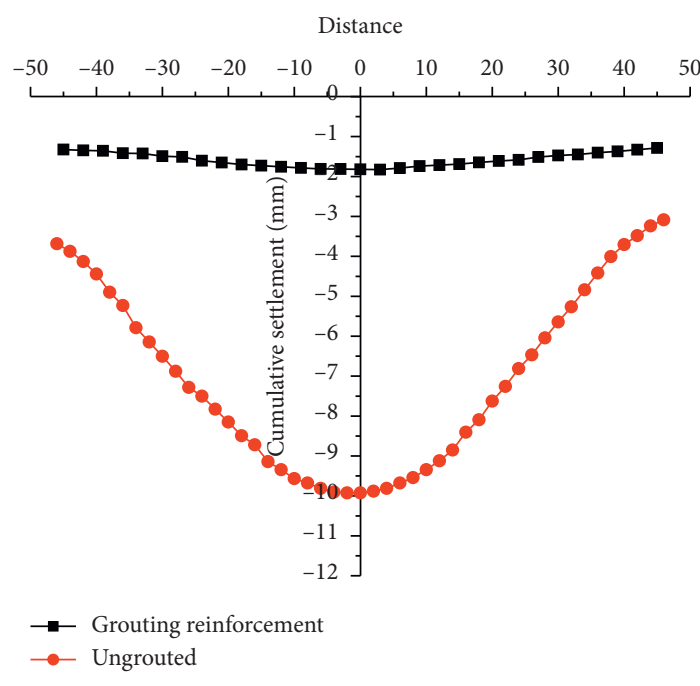

(a)

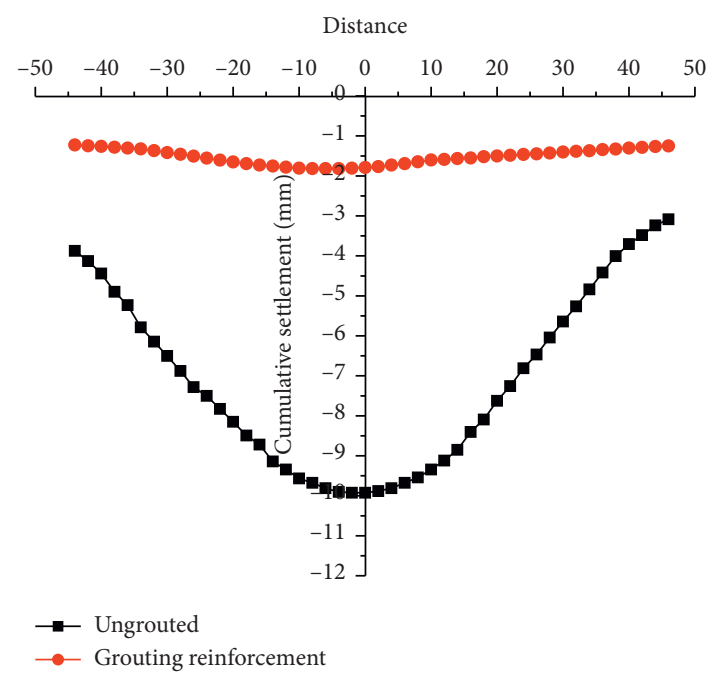

(b)

Figure 22: Comparison of settlement between subgrade and track before and after grouting. (a) Subgrade structure. (b) track structure.

TABLE 3: Comparison of monitoring results and numerical simulation.

\begin{tabular}{lccc}
\hline Reinforcement measures & Position & Monitoring $(\mathrm{mm})$ & Simulating value $(\mathrm{mm})$ \\
\hline \multirow{2}{*}{ Ungrouted reinforcement } & Subgrade structure & $\mathbf{9 . 9 2}$ & $\mathbf{9 . 8 9}$ \\
& Track structure & Act & $\mathbf{9 . 8 9}$ \\
\hline \multirow{2}{*}{ Grouting reinforcement } & Subgrade structure & $\mathbf{1 . 8 1}$ & $\mathbf{1 . 9 3}$ \\
& Track structure & $\mathbf{1 . 8 2}$ & $\mathbf{1 . 9 3}$ \\
\hline
\end{tabular}

construction, parameter adjustment, and optimization of the basis.

\section{Conclusions}

By means of numerical analysis and on-site monitoring, the disturbance law of the double-tunnel tunnel passing through the existing track project with small spacing is explored and the settlement deformation of the existing track is effectively controlled by adjusting the parameters of the shield machine and synchronous grouting reinforcement. The main conclusions are as follows:

(1) The settlement value and settlement trend of the existing track structure are basically the same as those of the roadbed structure. The maximum settlement of track and subgrade is located directly above the leftline tunnel when the left-line tunnel crosses the cross section. When the double-line tunnel crosses the cross section, the maximum settlement is located in the middle area of the two tunnels.

(2) In the process of settlement analysis, the maximum settlement is $9.89 \mathrm{~mm}$ by numerical calculation and $9.92 \mathrm{~mm}$ by field monitoring. The results are close to each other and the margin of error is $5.6 \%$. The numerical results can provide the design reference for construction.

(3) The construction of a double-line tunnel will produce a superposition effect, and the right-line tunnel will produce a secondary settlement in the left-line tunnel area. An alternative construction of the left and right tunnels can effectively reduce surface settlement.

(4) By adjusting the parameters of shield machine and ground grouting reinforcement and dynamically compensating grouting and following the synchronous grouting at different stages after passing through the grouting and the secondary grouting of segments, the settlement deformation can be effectively controlled within $2 \mathrm{~mm}$, and the requirements of the construction can be met.

In future research, pressure and displacement sensors can be installed at the interface of pile and soil to monitor the internal force and displacement of pile foundation. In view of the tunnel construction process, further analysis of the internal force of pile-soil and the displacement will be made.

\section{Data Availability}

The data used to support the findings of this study are included within the article.

\section{Conflicts of Interest}

The authors declare that there are no conflicts of interest regarding the publication of this paper. 


\section{Acknowledgments}

This study was funded by the Young Backbone Teachers Training Program for Colleges and Universities of Henan Province (2019GGJS223), Soft Science Research Program of Henan Province (20200106021), and Science and Technology Program of Henan Province (172102310459).

\section{References}

[1] X. Qi, W. Qiu, G. Gao et al., "Study on deformation law of double-line shield tunnel obliquely crossing underneath existing municipal tunnel," in Proceedings of the IOP Conference Series: Materials Science and Engineering, vol. 741, no. 1, p. 12025, Chennai, India, September 2020.

[2] M. Zhang, J. Fan, and B. Y. Pan, "Analysis on construction influence of the underpass of oblique crossing subway tunnel," Applied Mechanics and Materials, vol. 716, pp. 418-423, 2015.

[3] H. Fu, P. An, Z. Huang et al., "Determination of safety distance of twin tunnel underpassing existing tunnels," Advances in Environmental Vibration and Transportation Geodynamics, Springer, Berlin, Germany, 2020.

[4] B. Yuan, M. Sun, L. Xiong, Q. Luo, S. P. Pradhan, and H. Li, "Investigation of 3D deformation of transparent soil around a laterally loaded pile based on a hydraulic gradient model test," Journal of Building Engineering, vol. 28, no. 3, Article ID 101024, 2020.

[5] P. Lueprasert, P. Jongpradist, P. Jongpradist, and S. Suwansawat, "Numerical investigation of tunnel deformation due to adjacent loaded pile and pile-soil-tunnel interaction," Tunnelling and Underground Space Technology, vol. 70, pp. 166-181, 2017.

[6] E. Namazi, H. Mohamad, M. E. Jorat et al., "Investigation on the effects of twin tunnel excavations beneath a road underpass," Electronic Journal of Geotechnical Engineering, vol. 16, no. 1, pp. 1-8, 2011.

[7] A. Sirivachiraporn and N. Phienwej, "Ground movements in EPB shield tunneling of Bangkok subway project and impacts on adjacent buildings," Tunnelling and Underground Space Technology, vol. 30, pp. 10-24, 2012.

[8] W. Pan, Z. Gao, C. Zheng, and Z. Gong, "Analysis on the influence of cross tunnel construction on the deformation of the existing high-speed railway tunnel," Geotechnical and Geological Engineering, vol. 36, no. 6, pp. 4001-4013, 2018.

[9] Z. Yang, Y. Ding, Y. Jiang et al., "Study of the construction sequence of overlapping tunnels by the shield tunneling method: a case study of the longest overlapping tunnel in China," Advances in Civil Engineering, vol. 2020, Article ID 4909750, 9 pages, 2020.

[10] X. M. Guan, G. Wang, X. C. Wang et al., "Influences of shield tunnel construction of double-line Metro on settlement of existing pipeline," Journal of Engineering Science \& Technology Review, vol. 13, no. 2, 2020.

[11] J. F. Yang, Y. C. Zheng, Q. Chen et al., "A case study on settlement control of shield tunneling under existing metro tunnel," Tunnel Construction, vol. 39, no. S2, p. 385, 2019.

[12] J. Zhang, G. Huang, and X. Gou, "An optimum meta model for safety control of operational subway tunnel during underpass shield tunneling," Structural Control and Health Monitoring, vol. 25, no. 8, Article ID e2195, 2018.

[13] F. Lv, F. Ren, and L. Zhang, "Study on deformation influence of shield tunnel passing through existing railway bridge piles," in Proceedings of the IOP Conference Series: earth and
Environmental Science, vol. 189, no. 2, p. 22088, Chicago, IL, USA, December 2018.

[14] M. C. Zhang, "Settlement analysis and safeguard measures of underground tunnel crossing operating Metro," Building Technology Development, vol. 46, no. 13, pp. 41-43, 2019.

[15] Z. Yang and X. Wang, "Influence of Metro tunnel excavation on deformation of existing pedestrian underpass in changzhou railway station platform," IEEE Access, vol. 8, pp. 55860-55871, 2020.

[16] M. Zhang, H. Wan, W. Li et al., "Analysis of construction settlement of shield tunnel crossing Metro operating tunnel," MSé, vol. 782, no. 4, Article ID 42009, 2020.

[17] S.-M. Liao, C.-H. Cheng, and L.-S. Chen, "The planning and construction of a large underpass crossing urban expressway in Shanghai: an exemplary solution to the traffic congestions at dead end roads," Tunnelling and Underground Space Technology, vol. 81, pp. 367-381, 2018.

[18] Z. Huang, C. Zhang, H. Fu, H. Deng, S. Ma, and J. Fu, "Numerical study on the disturbance effect of short-distance parallel shield tunnelling undercrossing existing tunnels," Advances in Civil Engineering, vol. 2020, Article ID 8810658, 14 pages, 2020.

[19] B. X. Yuan, M. Sun, Y. Wang et al., "Full 3D displacement measuring system for 3D displacement field of soil around a laterally loaded pile in transparent soil," International Journal of Geomechanics, vol. 19, no. 5, Article ID 4019028, 2019.

[20] Y. H. Zhao, "Study on numerical simulation of underpass crossing existing subway tunnel in short distance," Urban Roads Bridges \& Flood Control, no. 11, pp. 141-145, 2015.

[21] H. Lai, H. Zheng, R. Chen et al., "Settlement behaviors of existing tunnel caused by obliquely under-crossing shield tunneling in close proximity with small intersection angle," Tunnelling and Underground Space Technology, vol. 97, Article ID 103258, 2020.

[22] W. Qi, Z. Yang, Y. Jiang et al., "Structural deformation of existing horseshoe-shaped tunnels by shield overcrossing," KSCE Journal of Civil Engineering, vol. 25, no. 2, pp. 735-749, 2020.

[23] B. Wu, M. Lu, W. Huang, Y. Lan, Y. Wu, and Z. Huang, "A case study on the construction optimization decision scheme of urban subway tunnel based on the TOPSIS method," KSCE Journal of Civil Engineering, vol. 24, no. 11, pp. 3488-3500, 2020.

[24] K. Wu, S. Cui, Y. Liu et al., "Study on the mechanism of grouting under different tunnel depth of cross passage," Geotechnical and Geological Engineering, vol. 38, no. 3, pp. 3291-3305, 2020.

[25] X. G. Li and D. J. Yuan, "Development of the safety control framework for shield tunneling in close proximity to the operational subway tunnels: case studies in mainland China," SpringerPlus5, vol. 527, 2016.

[26] J. Bai, S. Li, Y. Jiang, R. Liu, Z. Li, and W. Li, "An extension theoretical model for grouting effect evaluation in sand stratum of Metro construction," KSCE Journal of Civil Engineering, vol. 23, no. 5, pp. 2349-2358, 2019.

[27] C. Zhu, "Control of surface settlement by considering shield tunneling technology," KSCE Journal of Civil Engineering, vol. 21, no. 7, pp. 2896-2907, 2017.

[28] P. G. A. Njock, J. Chen, G. Modoni et al., "A review of jet grouting practice and development," Arabian Journal of Geoscience, vol. 11, p. 459, 2018.

[29] B. X. Yuan, L. Xiong, L. Zhai et al., "Transparent synthetic soil and its application in modeling of soil-structure interaction using optical system," Frontiers in Earth Science, vol. 7, p. 276, 2019. 
[30] Y. Yu, D. Chen, X. Zhao, X. Wang, L. Zhang, and S. Zhu, "Stabilization mechanism and safety control strategy of the deep roadway with complex stress," Advances in Civil Engineering, vol. 2020, Article ID 8829651, 18 pages, 2020.

[31] P. Zhang, Y. J. Pan, Z. C. Yu et al., "Ground subsidence characteristics caused by construction of shallow-buried tunnel in a sandy soil composite formation," Arabian Journal of Geoscience, vol. 13, p. 901, 2020. 